\title{
Efeito do aleitamento artificial à base de soro de queijo de leite cabra sobre as caracte- rísticas da carcaça e da carne de cabritos "mamão" do tipo genético three cross
}

\author{
Influence of the replacement of cow milk by goat milk cheese whey on meat composition carcass \\ characteristics of three cross suckling kids
}

\section{Frederico José Beserra ${ }^{1}$ Luciana Cristina Nogueira de Moraes Bezerra ${ }^{2}$ Elisabeth Mary Cunha da Silva ${ }^{3}$ Cláudio Ernani Mendes da Silva ${ }^{4}$}

\section{RESUMO}

\begin{abstract}
Avaliou-se a influência da substituição parcial na etapa de alimentação líquida do leite de vaca por soro de queijo de cabra (SLC) sobre alguns aspectos qualitativos da carne e quantitativos da carcaça de cabritos "mamão" Three cross (1/2 Anglonubiana $\times 1 / 4$ Pardo-Alpina $\times 1 / 4$ Moxotó), em quatro níveis: 0\% (Tratamento1); 20\% (Tratamento2); $40 \%$ (Tratamento3) $60 \%$ (Tratamento 4). Os pesos vivos ao abate (84 dias) mostraram-se homogêneos (10,88 a 13,42kg), assim como o rendimento de carcaça $(44,62$ a 47,86\%) e a área do Longíssimus dorsi $\left(9,55\right.$ a 10,80 $\left.\mathrm{cm}^{2}\right)$. 0 Tratamento 2 apresentou os maiores teores de tecido muscular (48,37\%). A composição centesimal mostrou valores médios entre 76,78 a 77,62\% de umidade; 20,39 a 21,43\% de proteina; 4,86 a 6,59\% de gordura e 1,06 a 1,14\% de cinza. Para os minerais estudados, os valores médios variaram de 16,77 a 35,68mg/100g para o cálcio; 110,33 a 153,90mg/100g para o fósforo; 1,29 a 2,17mg/100g para o ferro; 0,72 a 1,30mg/100g para magnésio; 128,86 a $165,94 \mathrm{mg} / 100 \mathrm{~g}$ para o sódio e 404,88 a 504,73mg/100g para o potássio. Concluiu-se que os níveis de soro de leite de cabra utilizados, de uma maneira geral, não tendo influenciado de forma significativa $(P<0,05)$ as variáveis estudadas, podem ser indicados até o nível de $60 \%$ de substituição, sem afetar o desenvolvimento corporal dos animais e a qualidade química de sua carne.
\end{abstract}

Palavras-chave: cabrito mamão, carne, composição de carcaça, substituição alimentar, soro de leite de cabra.

\section{ABSTRACT}

In this study, the influence of the replacement of cow milk by goat cheese whey on some quality aspects of meat and on some aspects of carcass composition of suckling kids Three cross (1/2 Anglonubiana x $1 / 4$ Pardo-Alpina $x \quad 1 / 4$ Moxotó) was evaluated. The replacements goat cheese whey levels were: $0 \%$ (treatment 1); $20 \%$ (treatment 2); $40 \%$ (treatment 3); $60 \%$ (treatment 4). The values of live weight for all were statistically similar (10.88 to $13.42 \mathrm{~kg})$; the same happened to the carcass yield which ranged from 44.62 to $47.86 \%$ and to the Longissimus dorsi area $\left(9.55\right.$ to $\left.10.80 \mathrm{~cm}^{2}\right)$. The treatment 2 showed the highest contents of muscular tissue (48.37\%). Proximal composition of the meat showed mean values ranging from 76.78 to $77.62 \%$ for moisture; 20.39 to $21.43 \%$ for protein; 4.86 to $6.59 \%$ for fat and 1.06 to $1.14 \%$ for ash. There was no significant difference among treatments. For mineral composition mean values ranged from 16.77 to $35.68 \mathrm{mg} / 100 \mathrm{~g}$ for calcium; 110.33 to $153.90 \mathrm{mg}$ / $100 \mathrm{~g}$ for phosphorus; 1.29 to $2.17 \mathrm{mg} / 100 \mathrm{~g}$ for iron; 0.72 to $1.30 \mathrm{mg} / 100 \mathrm{~g}$ for magnesium; 128.86 to $165.94 \mathrm{mg} / 100 \mathrm{~g}$ for sodium and 404.88 to $504.73 \mathrm{mg} / 100 \mathrm{~g}$ for potassium. It was concluded that the whey levels used in this study, did not influence in the parameters analyzed $(P<0,05)$. It can be indicated a replacement of up to $60 \%$ of whey on the animal diets without affecting their corporal performance and meat quality.

Key words: kids goat, meat quality, carcass composition, nutricional replacement, goat cheese whey.

\section{INTRODUÇÃO}

O Nordeste Brasileiro, com $1.640 .000 \mathrm{~km}^{2}$ ( $\approx 20 \%$ da área nacional) é caracterizado por reduzidas áreas férteis e tem na caprinocultura uma importante função social, por se constituir numa fonte de renda

${ }^{1}$ Departamento de Tecnologia de Alimentos, Centro de Ciências Agrárias, Universidade Federal do Ceará, Campus do Pici, CP 12168, Fortaleza-CE. E mail:beserra@ufc.br. Autor para correspondência.

${ }^{2}$ Centro de Tecnologia do Estado do Ceará - CENTEC, Limoeiro do Norte-CE.

${ }^{3}$ Agencia Nacional de Vigilância Sanitária - ANVISA, Ministério da Saúde, Brasília-DF.

${ }^{4}$ Departamento de Tecnologia de Alimentos, Centro de Ciências Agrárias, Universidade Federal do Ceará, Fortaleza-CE. 
para um grande contingente de pequenos produtores rurais e contribuir para a redução do déficit nutricional destas comunidades (PORTO, 1992; ANDRADE, 1984 e SILVA, 1984). Atualmente o mercado de carne caprina é muito promissor, existindo uma grande preferência pelo consumo de carne de cabritos de pouca idade (cabrito mamão), por apresentar características especiais, com relação ao sabor e textura .

Nos sistemas tecnificados de criação de caprinos com dupla função (produção de leite e carne), os cabritos são desmamados logo após a ingestão do colostro e aleitados artificialmente. Na maioria das vezes, este aleitamento consiste na administração de leite de vaca ocorrendo em idade precoce, visando à economia dos sistemas. Esta prática, contudo, é ainda onerosa dado o alto valor comercial do leite bovino. Por esta razão, a busca por sucedâneos lácteos que diminuam os custos da produção está sendo difundida (MONTENEGRO, 1996). A utilização do soro de queijo como sucedâneo lácteo do leite bovino tem representado uma opção de baixo custo para o criador na alimentação de suínos e bovinos (UGIETTE et al.1990). O soro de queijo apresenta um alto valor nutritivo e suas proteínas são valorizadas pelas suas propriedades funcionais e pelo seu alto valor biológico (DE WITT \& HON TELEZ,1981). O seu uso no aleitamento de cabritos, tem sido estudado por diversos autores como MONTENEGRO (1996) e PIMENTA FILHO et al. (1996), com resultados promissores.

O presente trabalho foi conduzido no sentido de avaliar o efeito da utilização do soro de queijo do leite de cabra como sucedâneo do leite bovino, sobre algumas características quantitativas da carcaça, bem como, algumas características químicas da carne de cabritos "mamão" do tipo genético cruza Three cross (1/2 Anglonubiano x 1/4 Pardo-Alpina X 1/4 Moxotó).

\section{MATERIAL E MÉTODOS}

Utilizou-se neste estudo um lote de 20 cabritos "mamão" do grupo genético cruza Three cross ( $1 / 2$ Anglonubiano x 1/4 Pardo-Alpina x 1/4 Moxotó) criados nas instalações da EMBRAPA, no Centro Nacional de Pesquisa de Caprinos (CNPC), situado em Sobral - CE. Para a aplicação do experimento, os cabritos, desmamados aos três dias de vida, foram selecionados aleatoriamente, alojados em gaiolas individuais e alimentados com leite de vaca tipo $\mathrm{C}$ na proporção de $20 \%$ do peso corporal, até completarem 24 dias de idade. A partir do $15^{\circ}$ dia de idade, sua complementação de dieta sólida foi constituída de ração concentrada e feno de leucena (Leucena leucocephala), ad libitum. Do $25^{\circ}$ ao $34^{\circ}$ dia de vida, foram submetidos a um período de adaptação ao soro de queijo. Do $35^{\circ}$ até $84^{\circ}$ dia e após separação aleatória em grupos de 5 animais, aos cabritos foram aplicados quatro planos alimentares, diferenciados por níveis de substituição do leite de vaca pasteurizado tipo $\mathrm{C}$ por soro de queijo de leite de cabra compondo os seguintes tratamentos: $\mathrm{T}_{1}=0 \%$ de soro; $\mathrm{T}_{2}=20 \%$ de soro, $\mathrm{T}_{3}=40 \%$ de soro e $\mathrm{T} 4=$ $60 \%$ de soro. Os animais com 84 dias de vida, foram pesados, abatidos e o rendimento de carcaça (RC) obtido com base no seu peso quente e trato gastrointestinal vazio. Após resfriamento por 24 horas a $0^{\circ} \mathrm{C}$ e umidade relativa de $95,0 \%$, as carcaças foram divididas em meias carcaças pela secção da coluna vertebral, pesadas e armazenadas a $-18,0^{\circ} \mathrm{C}$ por um período de 10 dias. Após o descongelamento, que ocorreu em câmara fria a $5,0^{\circ} \mathrm{C}$ e umidade relativa de 95,0\% (12,0-15,0 horas), foram separados, com o auxílio de um bisturi, os tecidos conjuntivo, adiposo, muscular e ósseo e seus rendimentos obtidos com base no peso da carcaça fria. Precedendo à desossa, as meias carcaças foram secionadas entre a 12 e $13^{\mathrm{a}}$ costela para a determinação da área transversal do músculo Longissimus dorsi, que foi realizada com um padrão transparente (ISUST,1975).

O tecido muscular obtido da desossa integral das carcaças foi utilizado para a realização das análises da composição centesimal e mineral. As análises de umidade, proteína, gordura e cinza seguiram a metodologia descrita pela ASSOCIATION OF OFFICIAL ANALYTICAL CHEMISTS (1990); as de cálcio, magnésio, sódio e potássio segundo HARRIS (1991); a de ferro segundo CHRISTIAN (1986), e as de fósforo, pela metodologia descrita pelo LANARA (1981). Para o estudo do efeito do plano alimentar (tratamento) sobre cada variável, utilizouse a técnica paramétrica de análise de variância (ANOVA) e comparações "a posteriori" (Teste de Tukey) com um nível de significância de 5,0\%, através do programa estatístico SAS (1999).

\section{RESULTADOS E DISCUSSÃO}

A análise dos valores médios e desvios padrões de peso vivo rendimento de carcaça e tecidos componentes, relação músculo/osso e área do músculo Longissimus dorsi dos cabritos “mamão", submetidos a distintos teores de soro de leite de cabra (SLC) expressos na tabela 1 , demonstrou que os animais do tratamento 4 apresentaram um peso vivo final $(10,88$ $\mathrm{kg})$, inferior aos demais tratamentos $(\mathrm{P}<0,05)$, 
Tabela 1 - Valores médios e desvios padrões de peso vivo $(\mathrm{Kg})$, rendimento de carcaça e tecidos componentes (gr/100g de amostra úmida), relação músculo/osso e área do músculo Longissimus dorsi $\left(\mathrm{cm}^{2}\right)$, dos cabritos "mamão" submetidos a distintos teores de soro de queijo de leite de cabra (SLC).

\begin{tabular}{lcccc}
\hline \multirow{2}{*}{ Variáveis } & \multicolumn{4}{c}{ Tratamentos } \\
\cline { 2 - 5 } & $\mathbf{T}_{\mathbf{1}}$ & $\mathbf{T}_{\mathbf{2}}$ & $\mathbf{T}_{\mathbf{3}}$ & $\mathbf{T}_{\mathbf{4}}$ \\
\hline Peso vivo & $11,67^{\mathrm{a}} \pm 1,59$ & $11,82^{\mathrm{a}} \pm 1,41$ & $13,42^{\mathrm{a}} \pm 1,15$ & $10,88^{\mathrm{a}} \pm 1,34$ \\
Rendimento de carcaça & $47,86^{\mathrm{a}} \pm 2,34$ & $46,52^{\mathrm{a}} \pm 1,83$ & $47,05^{\mathrm{a}} \pm 0,74$ & $44,62^{\mathrm{a}} \pm 2,35$ \\
Rendimento de tecido muscular & $48,15^{\mathrm{a}} \pm 2,04$ & $48,37^{\mathrm{a}} \pm 2,29$ & $47,82^{\mathrm{a}} \pm 1,38$ & $46,98^{\mathrm{a}} \pm 2,07$ \\
Rendimento de tecido ósseo & $29,34^{\mathrm{a}} \pm 8,18$ & $32,22^{\mathrm{a}} \pm 2,06$ & $30,97^{\mathrm{a}} \pm 1,05$ & $32,17^{\mathrm{a}} \pm 1,52$ \\
Rendimento de tecido adiposo & $7,38^{\mathrm{a}} \pm 1,11$ & $5,84^{\mathrm{ab}} \pm 1,16$ & $4,70^{\mathrm{b}} \pm 1,03$ & $5,57^{\mathrm{ab}} \pm 0,73$ \\
Rendimento de tecido conjuntivo & $12,46^{\mathrm{a}} \pm 1,87$ & $15,34^{\mathrm{a}} \pm 1,73$ & $12,81^{\mathrm{a}} \pm 2,42$ & $10,77^{\mathrm{a}} \pm 0,64$ \\
Relação músculo/osso & $1,52^{\mathrm{a}} \pm 0,28$ & $1,46^{\mathrm{a}} \pm 0,16$ & $1,60^{\mathrm{a}} \pm 0,07$ & $1,58^{\mathrm{a}} \pm 0,11$ \\
Área do Longíssimus dorsi & $9,80^{\mathrm{a}} \pm 1,84$ & $10,80^{\mathrm{a}} \pm 1,36$ & $10,17^{\mathrm{a}} \pm 1,62$ & $9,55^{\mathrm{a}} \pm 1,55$ \\
\hline
\end{tabular}

$\mathrm{T}_{1}-0 \%$ de soro de queijo de leite de cabra $+100 \%$ de leite de vaca; $\mathrm{T}_{2}-20 \%$ de soro de queijo de leite de cabra $+80 \%$ de leite de vaca; $\mathrm{T}_{3}-$ $40 \%$ de soro de queijo de leite de cabra $+60 \%$ de leite de vaca; $\mathrm{T}_{4}-60 \%$ de soro de queijo de leite de cabra $+40 \%$ de leite de vaca.

Valores com letras sobrescritas iguais em uma mesma linha não apresentam diferença significativa em nível de 5\% pelo teste de Tukey.

enquanto os tratamentos 1 e 2 registraram valores semelhantes $(11,67$ e $11,82 \mathrm{~kg}$ respectivamente $)$. O tratamento 3 apresentou uma média diferenciada $(13,42 \mathrm{~kg})$, fazendo supor a existência de diferenças entre este tratamento e os demais, não sendo, todavia, comprovado estatisticamente $(\mathrm{P}>0,05)$, talvez por causa da grande variabilidade desta variável dentro de cada tratamento.

Os valores médios de peso vivo, obtidos neste estudo (10,88 a $13,42 \mathrm{~kg})$, situam-se dentro do intervalo de valores citados na literatura que caracterizam pesos vivos de cabritos "mamão" de raças do nordeste brasileiro como os citados por SILVA (1997), entre 10,27 a 11,09kg, para animais da raça Moxotó e do grupo genético Moxotó x PardoAlpina, aleitados artificialmente com leite bovino e com idade média de 72 dias e por RIBEIRO et al.(1997), que citam peso médio de $12,14 \mathrm{~kg}$ para cabritos mestiços Pardo-Alpina x Gurguéia de 92 dias de idade, submetidos a 4 diferentes níveis de substituição de leite de cabra por soro de queijo bovino $(0,15,33$ e $69 \%)$ Quanto às médias de rendimento de carcaça, observou-se o maior valor para o tratamento $1(\mathrm{P}<0,05)$ e uma grande variabilidade dentro dos tratamentos 1,2 e 4 . O confronto estatístico destas médias, não registrou diferença significativa $(\mathrm{P}>0,05)$, entre os tratamentos. Valores da magnitude dos alcançados neste estudo foram obtidos por SANTOS FILHO (1997), que analisando o efeito do peso vivo ao abate sobre algumas características qualitativas e quantitativas em caprinos SRD do Ceará, encontrou, para grupos de peso de $20,0-22,9 \mathrm{~kg}$, rendimento de $37,41 \%$; entre
$23,0-25,9 \mathrm{~kg}$, de $46,48 \%$, entre $26,0-28,9 \mathrm{~kg}$, de $47,67 \%$ e para a faixa entre $29,0-31,9 \mathrm{~kg}$, rendimento de $49,98 \%$.

Rendimentos de carcaça inferiores aos deste estudo foram citados em raças nordestinas por BELLAVER et al. (1983) que obteve, em animais de diferentes raças, com cerca de um ano de idade, valores de rendimentos de carcaça quente em torno de 38,0\%. TIMBÓ (1996), igualmente estudando a evolução de algumas características da carcaça das cruzas $1 / 2$ Moxotó x 1/2 Pardo-Alpina e 1/4 Moxotó x 3/4 PardoAlpina durante um período de 3 e 8 meses, registrou no primeiro mês, um valor $40,0 \%$ e, no segundo, $41,0 \%$ de rendimento de carcaça, inferiores aos deste estudo. SILVA (1997) reporta para cabritos da raça Moxotó e grupos genéticos cruzas Pardo-Alpina x Moxotó, com peso vivo variando de 10,27 a $11,0 \mathrm{~kg}$, valores de rendimento de carcaça também inferiores, exceção feita aos animais da raça Moxotó que tiveram um rendimento médio de $48,10 \%$.

A análise de variância dos valores da área do músculo $\boldsymbol{L}$. dorsi, que mostra uma homogeneidade entre tratamentos $(\mathrm{P}>0,05)$, parece também indicar um desenvolvimento muscular análogo entre os mesmos, já que este parâmetro tem sido relacionado por autores como DELFA et al. (1992), como preditor do desenvolvimento muscular.

O maior valor médio aqui encontrado, $10,80 \mathrm{~cm}^{2}$ (tratamento 2), supera os citados para cabritos com pesos vivos semelhantes por SILVA (1997), na raça Moxotó e cruzas Pardo-Alpina x Moxotó, de $5,60 \mathrm{~cm}^{2}$ como valor máximo e por MASSARI et al.(1988), em caprinos da raça Pardo 
Alpina, uma área de 4,5cm². SHELTON et al. (1985), citam, em animais de diferentes raças do Nordeste Brasileiro valores entre 10,09 e 10,35 cm², análogos ao deste estudo. SANTOS FILHO (1997), ao trabalhar com caprinos SRD do Estado do Ceará abatidos em quatro faixas de peso vivo, $20,0-22,9 \mathrm{~kg}, 23,0-25,9 \mathrm{~kg}$, 26,0-28,9kg e 29,0-31,9kg encontrou áreas de 7,90, $9,33,13,37$ e $13,32 \mathrm{~cm}^{2}$, respectivamente. Valores semelhantes aos obtidos neste estudo, áreas em torno $10,66 \mathrm{~cm}^{2}$, também foram registrados por KAMBLE et al. (1989), em animais da raça Osmanabadi, com peso médio $13,9 \mathrm{~kg}$,

Quanto à composição dos tecidos componentes da carcaça, o tratamento 4 apresentou os menores percentuais de tecido muscular, enquanto os valores máximos foram registrados no tratamento 2. As diferenças observadas entre estes dois tratamentos não se mostraram, contudo, significativas estatisticamente $(\mathrm{P}>0,05)$. Os valores de rendimento de tecido ósseo apresentam-se homogêneos entre si ( $P>0,05)$, assim como os de tecido conjuntivo. Comportamento oposto foi observado para o rendimento de tecido adiposo no qual o teor médio mínimo foi registrado para o tratamento 3 e o valor máximo para o tratamento $1(\mathrm{P}<0,05)$.

Ao analisar-se a relação músculo/osso, observa-se que não houve efeito significativo entre tratamentos $(\mathrm{P}>0,05)$, evidenciando que a utilização dos diferentes níveis de soro de queijo de leite de

Tabela 2 - Valores médios $(\% \mathrm{p} / \mathrm{p})$ e desvios padrões da umidade, proteína, gordura e cinza , Ca, P, Fe, Mg, Na e P (mg/100g de amostra-base úmida), da carne de cabritos "mamão" alimentados com diferentes níveis de soro de leite de cabra (SLC).

\begin{tabular}{lcccc}
\hline \multirow{4}{*}{ Variáveis } & \multicolumn{4}{c}{ Tratamentos } \\
\cline { 2 - 5 } & $\mathbf{T}_{\mathbf{1}}$ & $\mathbf{T}_{\mathbf{2}}$ & $\mathbf{T}_{\mathbf{3}}$ & $\mathbf{T}_{4}$ \\
\hline Umidade & $76,78^{\mathrm{a}} \pm 0,79$ & $77,21^{\mathrm{a}} \pm 0,58$ & $77,62^{\mathrm{a}} \pm 0,72$ & $77,48^{\mathrm{a}} \pm 0,66$ \\
Proteína & $21,43^{\mathrm{a}} \pm 0,31$ & $20,85^{\mathrm{a}} \pm 0,33$ & $21,27^{\mathrm{a}} \pm 0,63$ & $20,39^{\mathrm{a}} \pm 0,37$ \\
Gordura & $6,59^{\mathrm{a}} \pm 0,76$ & $5,61^{\mathrm{a}} \pm 0,58$ & $5,21^{\mathrm{a}} \pm 1,52$ & $4,86^{\mathrm{a}} \pm 0,52$ \\
Cinza & $1,12^{\mathrm{a}} \pm 0,03$ & $1,06^{\mathrm{a}} \pm 0,04$ & $1,14^{\mathrm{a}} \pm 0,10$ & $1,09^{\mathrm{a}} \pm 0,04$ \\
Cálcio & $16,77^{\mathrm{a}} \pm 4,18$ & $33,65^{\mathrm{a}} \pm 8,81$ & $27,38^{\mathrm{a}} \pm 8,83$ & $35,68^{\mathrm{a}} \pm 5,90$ \\
Fósforo & $149,48^{\mathrm{a}} \pm 25,22$ & $153,90^{\mathrm{a}} \pm 25,80$ & $110,33^{\mathrm{b}} \pm 26,67$ & $120,49^{\mathrm{b}} \pm 10,02$ \\
Ferro & $1,29^{\mathrm{a}} \pm 0,11$ & $2,17^{\mathrm{b}} \pm 0,41$ & $2,08^{\mathrm{bc}} \pm 0,39$ & $1,47^{\mathrm{ca}} \pm 0,17$ \\
Magnésio & $0,72^{\mathrm{a}} \pm 0,14$ & $1,30^{\mathrm{b}} \pm 0,24$ & $1,03^{\mathrm{ab}} \pm 0,09$ & $1,07^{\mathrm{ab}} \pm 0,12$ \\
Sódio & $160,58^{\mathrm{a}} \pm 40,75$ & $139,25^{\mathrm{a}} \pm 18,29$ & $128,86^{\mathrm{a}} \pm 12,48$ & $165,94^{\mathrm{a}} \pm 19,76$ \\
Potássio & $406,53^{\mathrm{a}} \pm 77,11$ & $504,73^{\mathrm{a}} \pm 16,49$ & $404,88^{\mathrm{a}} \pm 35,64$ & $442,07^{\mathrm{a}} \pm 38,58$ \\
\hline
\end{tabular}

$\mathrm{T}_{1}-0 \%$ de soro de queijo de leite de cabra $+100 \%$ de leite de vaca; $\mathrm{T}_{2}-20 \%$ de soro de queijo de leite de cabra $+80 \%$ de leite de vaca; $\mathrm{T}_{3}-40 \%$ de soro de queijo de leite de cabra $+60 \%$ de leite de vaca; $\mathrm{T}_{4}-60 \%$ de soro de queijo de leite de cabra $+40 \%$ de leite de vaca.

Valores com letras sobrescritas iguais, em uma mesma linha, não apresentam diferença significativa em nível de $5 \%$ pelo teste de Tukey. cabra, neste trabalho, não influenciou o grau de musculosidade da carcaça. Este resultado, bem como os obtidos para peso vivo, rendimento de carcaça e tecidos componentes, demonstra não haver prejuízo ao desenvolvimento corporal dos animais em função da substituição estudada, em seus diferentes níveis.

A tabela 2 apresenta os valores médios e desvios padrões de umidade, proteína, gordura e cinza, cálcio, fósforo, ferro, magnésio, sódio e potássio, assim como das comparações "a posteriori", da carne de cabritos mamão submetidos a diferentes níveis de soro de leite de cabra (SLC).

No referente à composição centesimal, observa-se que os diferentes níveis de substituição não interferiram significativamente $(\mathrm{P}>0,05)$, nos teores de proteína, umidade, cinza e gordura presentes no tecido muscular, o que parece indicar que a iodisponibilidade desses nutrientes, nas diferentes dietas, foi a mesma. Os resultados reportados na al. (2001); MADRUGA et al. (1999); LEITE (1997); TIMBÓ (1996); BABIKER et al. (1990); KONDAIAH \& SHARMA (1989); GONZALEZ et (1983); PARK et al. (1991); DATTILO \& GONGIÜ mostram-se, em geral, semelhantes nas teores de gordura e umidade as maiores variações. Confrontando-se os percentuais aqui obtidos com os de animais nordestinos na mesma faixa de idade e/ou peso ao abate, verifica-se que apresentam teores de proteína umidade, cinza semelhantes e inferiores de gordura. ROCHA (1997), analisando as características sensoriais e físico-químicas de cabritos "Three cross" de 84 dias, reporta valores de 74,93 a $76,50 \%$ para umidade; 21,36 a $23,24 \%$ para proteína e de 1,39 a 1,69\%.para gordura. Em cabritos "mamão" com idade média de 72 dias, da raça Moxotó e cruzas Pardo-Alpina x Moxotó, BESERRA et al. (2000), encontraram uma umidade entre 77,80 a $80,25 \%$, cinza entre 1,29 a $2,03 \%$, e inferiores de proteína $(15,90$ a $19,08 \%)$ e gordura $(1,13$ a $1,21 \%)$. ZAPATA et al. (1995), estudando o efeito da adição de ferro injetável como suplemento à dieta de cabrito mamão cruza 1/2 Moxotó x $1 / 2$ PardoAlpina, citam, para animais com 63 dias de idade, valores de umidade de 73,72 a $74,41 \%$ e proteína, 8,52 a

Ciência Rural, v. 33, n. 5, set-out, 2003. 
$19,17 \%$ ), cinza , 1,00 a $1,12 \%$ e de gordura entre 3,52 a $4,6 \%$. Comparando-se com os valores registrados na literatura internacional por PARK et al. (1991); BABIKER et al.(1990); KONDAIAH \& SHARMA (1989); GONZALEZ (1983); DATTILO \& GONGIÙ (1974), observam-se intervalos semelhantes para os conteúdos de proteína, cinza e umidade, e valores de gordura sempre inferiores aos deste estudo, mesmo em animais com maior faixa de idade, ou peso ao abate.

A análise da composição mineral nos mostra variações acentuadas entre tratamentos, registrando-se, contudo, diferenças significativas $(\mathrm{P}<0,05)$ apenas para fósforo, ferro e magnésio. Constata-se ainda que o tratamento 1 , no que se refere aos conteúdos de ferro e magnésio, apresentou valores inferiores à pelo menos um dos demais tratamentos $(\mathrm{P}<0,05)$, ao contrário do esperado, já que os animais alimentados com leite de vaca deveriam apresentar maior concentração desses minerais, uma vez que o seu conteúdo no leite de vaca é superior ao do soro de queijo (SINN, 1983; AGRICULTURE HANDBOOK,1976). Este comportamento pode ser atribuído à baixa disponibilidade biológica do ferro e magnésio no leite de vaca, em relação ao soro de queijo de leite de cabra, uma vez que a digestibilidade desses minerais, segundo LOBÃO \& VITTI (1977), depende entre outros fatores da forma química como eles apresentam-se no alimento.

Ao fazer-se uma comparação dos valores em magnésio na carne caprina reportados na literatura por BESERRA et al. (2000); BESERRA et al. (2001); TIMBÓ, (1996); PARK (1990); CASEY (1992), observa-se uma baixa concentração deste mineral na carne. Este fato poderá ser explicado pela eimeriose que acometeu os animais durante a fase experimental. Esta doença, causada por protozoários, provoca um quadro de diarréia que, segundo PORTELA (1982), é um dos fatores responsáveis pela diminuição do magnésio no organismo.

O baixo conteúdo de Ferro aqui obtidos (1,29 a $2,17 \mathrm{mg} / 100 \mathrm{~g}$ ), que é inferior aos reportados para caprinos do Nordeste Brasileiro por MADRUGA, (1999) e BESERRA et al.(2001), coincide com teores citados por BESERRA et al. (2000) e ZAPATA et al. (1995). Este fato era esperado ao considerar-se o plano nutricional pobre em ferro a que foram submetidos. Também é relevante a baixa idade dos animais estudados uma vez que este conteúdo é proporcional à concentração de mioglobina, cujo conteúdo é baixo em animais de pouca idade (LAWRIE, 1998, JAY \& FOX, 1994).

Os conteúdos de cálcio, sódio e fósforo que variaram entre $16,77\left(t_{1}\right)$ e $35,68 \mathrm{mg} / 100 \mathrm{~g}\left(\mathrm{t}_{4}\right)$,
$128,86 \mathrm{mg} / 100 \mathrm{~g}\left(\mathrm{t}_{3}\right)$ a $165,9 \mathrm{mg} / 100 \mathrm{~g}\left(\mathrm{t}_{1}\right), \mathrm{e}, 110,33\left(\mathrm{t}_{3}\right)$ e $153,90 \mathrm{mg} / 100 \mathrm{~g}\left(\mathrm{t}_{2}\right)$ respectivamente, concordam os dados relatados por BESERRA et al. (2001), BESERRA et al. (2000), CASEY (1992), PARK (1990), ALMEIDA (1990), para raças e grupos genéticos nordestinos e de diferentes partes do mundo.

$\mathrm{O}$ teor de fósforo na carne dos animais com níveis de substituição de 40 e $60 \%\left(\mathrm{t}_{3}\right.$ e $\left.\mathrm{t}_{4}\right)$, apresentaram níveis significativamente menores $(\mathrm{P}<0,05)$ que os das carnes dos alimentados com 0 e $20 \%$ de soro de leite de cabra. Na literatura consultada, não se encontrou informação que justificasse este fato.

\section{CONCLUSÕES}

Os valores encontrados para peso vivo, rendimento de carcaça e área do $\boldsymbol{L}$. dorsi, demonstram não haver efeito desfavorável da substituição do leite de vaca pelo soro de queijo de leite de cabra no desenvolvimento corporal dos animais estudados. As características nutricionais, no que se refere à composição centesimal e mineral do tecido muscular dos animais, nos diferentes tratamentos, apresentaramse análogos às descritas na literatura para animais desta faixa de idade e peso, com exceção ao conteúdo de magnésio que se apresentou abaixo dos níveis mínimos, o que pode ter sido causado pela eimeriose que acometeu os animais durante o experimento. A substituição do leite de vaca por soro de queijo de cabra nos níveis de 20 a $60 \%$ poderá ser utilizada, sem que ocorra prejuízo qualitativo na produção de cabritos "mamão" da raça Three cross, proporcionando a minimização dos custos de produção destes animais.

\section{REFERÊNCIAS BIBLIOGRÁFICAS}

AGRICULTURE HANDBOOK. Composition of foods. Washington : Department of Agriculture, 1976. 375p.

ALMEIDA, M.M. Estudo da composição química das carnes de caprinos e ovinos no sertão do Ceará. 1990. 78f. Dissertação (Mestrado em Tecnologia de Alimentos) - Curso de Pós-graduação em Tecnologia de Alimentos, Universidade Federal do Ceará

ANDRADE, I.V. Semi-árido e caprinos. Recife-PE : MINTER/ SUDENE, 1984. 18p.

AOAC. Official Methods of Analysis. Association of Official Analytical Chemists. Washington, 1990. 1018p.

BABIKER, S.A.; KHIDER, J.A.E.; SHAFIE, S.A. Chemical composition and quality attributes of goat meat and lamb. Meat Science, v.28, p.273-277, 1990.

BELLAVER, C. et al. Carcass characteristics of goats and sheep in Northeast Brazil. Pesquisa 
Agropecuária Brasileira, Brasília, v.3, p. 301-309, 1983.

BESERRA, F.J. et al. Caracterização química da carne de cabrito da raça Moxotó e de cruzas Pardo Alpino x Moxotó. Pesquisa Agropecuária Brasileira, Brasília, v.35, p.171-177, 2000.

BESERRA, F. J. et al. Características químicas e físico-químicas da carne de caprinos SRD com diferentes pesos ao abate. Tecnologia e Ciência de Carnes, Campinas, Brasil, v.3, n.2, p.1-7, 2001.

CASEY, N.H. Goat meat in human nutrition. In: INTERNATIONAL CONFERENCE ON GOATS, 5., 1992, New Delhi. Pre-conference proceedings... New Delhi : Indian Council of Agricultural Reserarch, 1992. V.2, pt2. p.581-598.

CHRISTIAN, G.D. Analytical chemistry. 4.ed. New York: John Wiley \& Sons, 1986. 599p.

DATTILO, M.; GONGIÚ, F. Raffronto delle caratteristiche chimico-fisiche fra le carni di capretto e d'agnello. Atti Società Italiana Scienze Veterinarie, Sassari, v.27, p.437-441, 1974.

DE WITT, J.N.; HON TELEZ, E.B. Les proprietés functionelles des proteínes du lactosérum: conséquences des traitements thermique. La Technologie Laitiére, Paris, n.952, p.19-22, 1981.

DELFA, R.; TEIXEIRA, A.; GONZÁLEZ, C. Composición de la canal. Medida de la composición. Ovis, n.23, p.09-22, 1992.

GONZALEZ, N.F.A.; OWN, J.E.; CERECERES, M.T.A. Studies on the Criollo goat of northern Mexico: Part 2 - Physical and chemical characteristics of the muscle. Meat Science, v.9, p.305314, 1983.

HARRIS, D.C. Quantitative chemical analysis. New York : W.H. Freeman, 1991. 782p.

ISUST - IOWA STATE UNIVERSITY OF SCIENCE AND TECNOLOGY. Transparent standart scale for Longissimus dorsi area. Iowa - USA, 1975.

JAY, B.; FOX, JR. Los pigmentos de la carne. In: PRICE, J.P.; SCHWEIGERT, B.S. Ciencia de la carne y de los productos cárnicos. 2.ed. Zaragoza : Acribia, 1994. p.175-198.

KAMBLE, V.J. et al. Quality aspect of Osmanabadi goat meat. Journal of Food Science Technology, v.26, n.2, p.99-101, 1989.

KONDAIAH. N.; SHARMA, N. Improving the quality of goat meat. Indian Journal of Animal Science, v.59, n,1, p.152-157, 1989.

LANARA - Métodos analíticos oficiais para controle de produtos de origem animal e seus ingredientes. II - Métodos químicos e físicos. Brasília : Ministério da Agricultura-Secretaria Nacional de Defesa Agropecuária, 1981. p.III.3.

LAWRIE, R.A. Constitución química y bioquímica del músculo. In: Ciencia de la carne. 3.ed. Zaragoza : Acribia, 1998. p.67108.

LEITE, A.M. Efeito da idade na composição centesimal, teor de colesterol e perfil de ácidos graxos da carne de caprinos do Estado do Ceará. 1999. 68f. Dissertação (Mestrado em Tecnologia de Alimentos) - Curso de Pós-graduação em Tecnologia de Alimentos, Universidade Federal do Ceará.
LOBÃO, A.O.; VITT, D.M.S.S. Disponibilidade biológica de minerais para ruminantes. In: SIMPÓSIO SOBRE NUTRIÇÃO DE BOVINOS, 1977, Piracicaba. Anais... Piracicaba : Escola Superior de Agricultura, 1977. p.50-104.

MADRUGA, M.S. et al. Castration and slauge age effects on nutritive value of the "mestiço" goat meat. Meat Science, London, v.52, p.119-125, 1999.

MASSARI M. et al. Carcass characteristics of male Alpine kids slaughtered at different weights. Small Ruminant Research, v.1, p.49, 1988.

MONTENEGRO, M.P. Substituição do leite de vaca por soro de queijo de cabra no aleitamento artificial de cabritos. 1996. 64f. Dissertação (Mestrado em Tecnologia de Alimentos) - Curso de Pós-graduação em Tecnologia de Alimentos, Universidade Federal do Ceará.

PARK, Y.W. Effect of breed, Sex and tissues on concentration of macrominerals in goat meat. Journal of Food Science, v.55, n.2, p.308-311, 1990.

PARK, Y.W. et al. Moisture, total fat and cholesterol in goat organ and muscle meat. Journal of Food Science, v.56, n.5, p.11911193, 1991.

PIMENTA FILHO, E.C.; UGIETTE, S.M.A.; ALMEIDA, C.C. Efeito da substituição do leite de cabra por soro de queijo no crescimento de cabritos na fase de aleitamento. Revista da Sociedade Brasileira de Zootecnia, v.25, n.3, p.522-528, 1996.

PORTELA, M.L.P.M. Revisión de los conocimientos actuales acerca de la evaluación del estado nutricional de los elementos minerales. Archivo Latinoamericano de Nutrición, v.32, p.238237,1982 .

PORTO, E.R. Desenvolvimento sustentável no semi-árido brasileiro. In: Impactos de variações climáticas de desenvolvimento sustentável em regiões semi-áridas. Petrolina : EMBRAPA-CPATSA, 1992. 70p.

RIBEIRO, M.N. et al. Características físico-químicas da carne de caprinos submetidos a diferentes níveis de substituição do leite por soro de queijo durante o aleitamento. Revista da Sociedade Brasileira de Zootecnia, v.26, n.3, p.595-598, 1997.

ROCHA, S.M.R. Influência de diferentes planos nutricionais sobre algumas características sensoriais da carne de cabrito mamão da raça cruza Three cross. 1997. 65f. Dissertação (Mestrado em Tecnologia de Alimentos) - Curso de Pósgraduação em Tecnologia de Alimentos, Universidade Federal do Ceará.

SANTOS FILHO, J.M. Efeito do peso vivo ao abate sobre algumas características quantitativas e qualitativas das carcaças de caprinos SRD no estado do Ceará. 1997. 78f. Dissertação (Mestrado em Tecnologia de Alimentos) - Curso de Pós-graduação em Tecnologia de Alimentos, Universidade Federal do Ceará.

SAS-STST. The SAS system for windows version 8.0. Carry, NC.USA : SAS Institute, 1999. 3 CD-ROM.

SHELTON, M.; SNOWDER, G.; FIGUEIREDO, E.A.P. Meat production and carcass characteristics of the goat. Small Ruminant Collaborative Research Support Program. v.45, p.126, 1985. 
SILVA, M.T. Estudo do rendimento de carcaça e de algumas propriedades funcionais da carne de cabrito mamão da raça Moxotó e cruzas Pardo-Alpina x Moxotó. 1997. 60f. Dissertação (Mestrado em Tecnologia de Alimentos) - Curso de Pós-graduação em Tecnologia de Alimentos, Universidade Federal do Ceará.

SILVA, A.G.S. Efeito do sistema de criação e época de abate sobre algumas características em caprinos SRD. 1984. 54f. Dissertação (Mestrado em Zootecnia) - Curso de Pós-graduação em Zootecnia, Universidade Federal de Minas Gerais.

SINN, R. Raising goats for milk and meat. Arkansas : A Heifer Profect International Training Course, 1983. 72p.

TIMBÓ, M.O.P. Estudo da evolução da composição centesimal de algumas físicas e funcional da carne de caprino de híbridos das raças Pardo Alpina x Moxotó. 1996. $101 \mathrm{f}$.
Dissertação (Mestrado em Tecnologia de Alimentos) - Curso de Pós-graduação em Tecnologia de Alimentos, Universidade Federal do Ceará

UGIETTE, S.M.A. et al. Análise econômica da utilização de resíduo de indústria de queijo (soro de leite) em substituição ao leite de cabra na alimentação artificial de cabritos. In: SIMPÓSIO NORDESTINO DE NUTRIÇÃO DE RUMINANTES, 3., 1990, João Pessoa-PB. Anais... João Pessoa : Universidade Federal da Paraíba, 1990. p. 159

ZAPATA, J.F.F.; BARROS, N.N.; VASCONCELOS, N.M.S. Carcass tissue distribution and composition of the lean meat from kids fed na iron supplemented diet. In: INTERNATIONAL CONGRESS OF MEAT SCIENCE AND TECHNOLOGY, 41., 1995, USA. Proceedings... USA : America Meat Science Association, 1995. p.40-42. 